\title{
ANALYTICAL CHEMISTRY IN THE INTEREST OF THE PUBLIC
}

\begin{abstract}
HE recently published report of the Government Chemist * has given Dr. D. T. Lewis the opportunity to review the wide range of work done in his Laboratory during 1963. This annual publication by the Department of Scientifie and Industrial Research always contains a good deal of material of interest particularly to analytical chemists, but much of its content is of more than passing interest to the general public whose interests the Laboratory exists to serve.

By far the largest amount of work, occupying at least half the total effort of the Laboratory, is for H.M. Customs and Excise, the requirements of which for the year have involved the Laboratory in the examination of more than a quarter of a million samples of various dutiable commodities, such as sugar, wines and. spirits, beers and marked gas oils. This is the bread and butter work of the Laboratory and involves well-established and routine analytical operations. Occasionally, however, problems arise which involve some original research, and the report of this can provide an interesting facet of the work of the Laboratory.

The examination of brandies and whiskies by the techniques of vapour-phase chromatography is one such example. These new techniques would appear to provide much more reliable means for the determination of the higher alcohols in these spirits than the existing spectrophotometric methods. These higher alcohols-in the main, $n$-propanol, iso-butanol, iso- and active pentanols, with occasional appreciable amounts of sec-butanoldiffer quite significantly in their relative amounts from one type of spirit to another; in general, brandy contains more of them than a blended Scotch. Gas-liquid chromatography has also been used to identify the 'secondaries' in brandy, and an interesting chromatogram of an ether$n$-pentane extract of the spirit has shown the presence
\end{abstract}

- Department of Scientific and Industrial Research: Laboratory of the port of the Government Chemist, 1963. of a considerable number of individual compounds; twenty-three of these have, in fact, been identified by comparison with chromatograms of mixed higher alcohols and ethyl esters of the $n$-fatty acids. Obviously this work is of importance in characterizing various types of spiritous beverages; with the considerable increase in the number of samples of illicitly distilled spirits seized by the Excise men during the year, the Laboratory is anxious to have more satisfactory methods for the comparison of these illicit spirits and commercially produced duty-paid spirits. Dr. Lewis remarks that many of these illicit spirits now attain an unusually high quality and one is left wondering if this is in some way related to the more widespread scientific education now available in Britain since the Second World War. By all accounts, a more discerning 'hooch-maker' is now emerging, which makes the detection of illicit spirits all the more difficult.

The work of the Government Chemist does, however, extend to fields other than those of the Customs and Excise, and much general analytical work is done for various Government Departments. Matters of public health are dealt with by the Laboratory and particular attention is directed to the examination of water and sewage, and to the analysis of suspected foods and drugs.

The Laboratory has only recently acquired its new accommodation in Cornwall House, and for the first time for many years most of the major activities of the Laboratory come under one roof. As this report indicates, a good deal of research and development work is necessary for the satisfactory functioning of the Laboratory; centralization of staff and equipment is bound to have a beneficial effect not only on research but also on the general work of the Laboratory. The present report gives an informative and very readable account of the year's activities of the Laboratory and shows how well the interests of the public are safeguarded over an extremely wide range of subjects.
W. I. STEPHEN

\section{SPECIAL PROBLEMS IN STUDYING WOODY PERENNIALS}

\begin{abstract}
$\mathrm{A}^{\mathrm{N}}$ unusual kind of conference was held at East Malling Research Station during July 20-24. The opportunity of the migration of scientists from many parts of the world to the tenth International Botanical Congress in Edinburgh in early August was seized to invite some forty of these, whose common interests related to some aspect of tho growth and fruiting of woody perennials, to gather at the Research Station. The conference was unique in two ways; first the special nature of the common theme and, second, the fact that no set papers were given but discussion was wholly spontaneous and free throughout the five days.

Nover before has the woody perennial, per se, been the theme of a single conference. Fruit crops, tropical crops, climatic groups, botanical or ecological relationships or physiological problems are the usual groupings, and thus workers on fruit crops, rubber, tea, citrus, or forest trees find their interests in a wide variety of sections at any one conference; rarely will they meet to discuss problems which are, in fact, closely allied. This was one of the outstanding features of the East Malling symposium; foresters, horticulturists, physiologists, biometricians, biochemists, ecologists, pathologists and entomologists all mingled in 'free association' to debate the common issues arising from investigations of a type of plant characterized
\end{abstract}

by a lignified, perennating structure, usually, though not always, formed from a sheathing meristem.

The second unique feature was the absence of prepared papors. A programme of themes for discussion had been arranged to provide a skeleton to be clothed but, at each session, after a brief and provocative opening statement by the chairman, diseussion was free and open without time-limit. Since everyone talked without notes or prepared data contributions were brief and to the point, dealing mainly with essential principles rather than the finer details.

In order to make it possible for everyone to join in discussion and to allow of deeper consideration of aspects of especial interest, two half-days were devoted to group meetings of some six to twenty members. The four general discussions were on the themes of the special nature of investigations on woody perennials, modifications of the crop plant imposed by man (for example, pruning, spacing, plucking, tapping), the influence on the woody crop plant of other plants (for example, weeds, cover crops, rotations, replant problems, and pests and diseases), and the description and measurement of tree form, size, and efficiency. The group discussions ranged over such topics as growth and cropping, juvenility, differentiation and flower initiation, natural growth substances, absorption, 
phloom transport and root/shoot relationships, and leaf efficiency and internal competition.

In so wide and varied a field it is difficult to seloct outstanding aspects, but one general point of interest was that there seemed less tendency than usual to attempt to explain all features of plant behaviour in torms of the production and distribution of growth substances or hormones. There was, of course, much discussion and argument on the role and modo of action of growth regulators in plant differentiation and general physiology, but organic metabolites seemed to come back more into their own, as it were, in the debates. Many spcakers stressed that growth substances had important effects in mediating the distribution of assimilates and there seemed to ba an undercurrent of feeling, not specifically expressed, that local concentrations of assimilates were involved in determining tissue behaviour, especially differentiation.

An interesting suggestion, which might well have been followed up, was that since virus infection in some plants (for example, apples) may alter the balance between flower initiation and vegetative growth, viruses might possibly be very useful tools in physiological investigations.

The contrast in outlook of the forestry worker, concerned primarily with the maximum production and quality of the woody parts of the plant, and the pomologist concerned with the maximum production and quality of fruit, led to interesting comparisons of experimental techniques and interpretations, undoubtedly of great value to both groups.

The visitors were the guests of members of the staff throughout the week and this proved a particularly happy feature of the gathering, which, despite the informality of its proceedings, clearly owed much of its undoubted success to careful preparations in advance. The news that it was planned to arrange further group discussions of this nature at East Malling in the future was warmly welcomed by all the guests who had shared in this experiment.

R. H. Stoughton

\section{THE ART OF CALLIGRAPHY}

$\mathrm{T}$ HE real meaning of the word calligraphy is 'beautiful' handwriting, not just 'handwriting' as often interpreted. Handwriting is essentially a medium of recording and transmitting information. As such, in various guises, sometimes readable, often decipherable with difficulty, it has evolved with history throughout the ages, reflecting contemporary styles, motives, the basis of literature, learning and culture, such as we now accept as a natural heritage. Much modern handwriting is of necessity hasty, essentially individual, executed with little, if any, regard for appearance or consideration of its impression on the recipient at the time, or on posterity if worthy of such survival. It is a rather frightening thought that, to-day, illegible signatures appended to important official and business correspondence (by no means confined to the professions most commonly criticized for this fault) have increasingly to be translated into block letters to establish identity. Not so in the Arab world, where calligraphy is, and always has been, something a great deal more, "... an art-indeed the chief form of visual art-with a history, a gallery of great masters and hallowed traditions. It is an art of grace and elegance which inspires wonderment for its appearance alone. What distinguishes calligraphy from ordinary handwriting is, quite simply, beauty".

The quotation comes from Kamel al-Baba, one of the contributors to Aramco World, a bi-monthly publication of the Arabian American Oil Company (15, No. 4; JulyAugust 1964, New York). "To the Arab world calligraphy is more than handwriting. It is a 'spiritual technique' that reaches out with grace and elegance to engage the eye, mind and soul ..." This article, well written and beautifully illustrated, clearly shows how throughout the centuries the Islamic religion has dominated both thought and actions of the Arab world. The Koran (or properly Qur'ān), "as the word of God revealed to Muhammad in the Arabic tongue", has been the inspiration of generations of calligraphers seeking to present its words down the ages with an ever-increasing perfection of style worthy of its contents. From relatively crude graphic representations of human beings and animals, to spread the divine message, the creative energies of Muslim artists tended towards more and more decorative work, thence to calligraphy in the real sense. The Koran is probably the most widely owned and widely read book in the Muslim world. Hence beautiful transcripts of this book are, as Kamel al-Baba says, powerful and constant.

The finding and winning of oil in Arabia have brought about revolutionary changes, not only in economic and political evolution of this hitherto little-known territory, but also equally in our knowledge of its people, their history, traditions, and modern reactions to a new life which, only a matter of a decade or so ago, would, to them, have appeared unreal and mythical. But one thing will certainly not change fundamentally: the art of expression of deep-rooted doctrines, simple beliefs, and a code of existence which only the hand in painting or writing can convey. Calligraphy may be a dying art in the Western world, but this is certainly not so in the Arab world.

Aramco World, concerned as it is with the modern Arabian scene, is doing a great service in teaching us all the facts as they are in the background, not just simply as we would perhaps like to imagine them.

\section{A MOON GLOBE}

DART of the value of a well-prepared globe of the Moon is that it emphasizes the overall distribution of maria, walled plains, craters, ray systems and other surface features. It also shows them in rectified form instead of by the standard orthographic projection used in most major lunar maps. As a result, features on the far side, photographed by Lunik 3, can be seen in topographic relationship with those near the Moon's limb. Of course, the value of a globe for investigations of this kind will depend on how precise it is with regard to positions, dimensions and content.

The Pergamon moon globe*, $33 \mathrm{~cm}$ in diameter, has a latitude-longitude grid at $10^{\circ}$ intervals, and on average

* The Pergamon Moon Globe. (Oxford: Pergamon Press, Ltd., 1964.) the position of a crater is accurate to about $\frac{1}{2}^{\circ}$. The maria are grey-green in colour, the highlands and craters greenishwhite, with shading to give an additional semblance of relief. Unfortunately, the shading is used so frooly as to make it well-nigh impossible in many cases to distinguish small craters from hills, ridges from mountain ranges and bright rays from ridges. The remarkable Triesnecker-Hyginus-Ariadaeus rill system, for example, is reproduced as a single, broad sinuous line, the crater Bessel in Mare Serenitatis looks like a lofty mountain, while Plato, Fra Mauro, Cassini, Archimedes and several other craters possess what appears to be central mountain peaks. Many craters are difficult to identify since they bear little or no resemblance to their counterparts on standard maps and photographs. This is a serious defect 